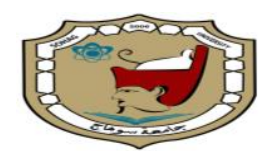

\title{
Ultrasound-guided foam sclerotherapy of lower limb varicose veins: outcome and patient satisfaction
}

\author{
Waleed A. Abd Elkhalek Elmadany ${ }^{1}$, Mohamed Tharwat M. Solyman ${ }^{1}$, \\ Mohammad Zaki Ali Mourad ${ }^{1}$, Khaled M. Helmy El-kaffas² .
}

1- Department of Diagnostic Radiology, Faculty of Medicine. Sohag University

2- Department of Interventional Radiology, Faculty of Medicine, Cairo University

\begin{abstract}
:
Background: Varicose veins are defined as dilated, tortuous, and elongated superficial veins of the lower limbs with incompetent valves. Varicose veins are described by the World Health Organization (WHO) as dilatation of the veins, which are sometimes tortuous. Varicose veins are divided into primary and secondary varicose veins according to their etiology. Sclerotherapy could be a minimally invasive technique that uses an injection of a special chemical (sclerosant) into varicosity to wreck and scar the inside lining of the vein. Resulting in blockage of the treated vein.

Patients and Methods: This study was conducted at Sohag University hospitals to evaluate the efficacy, safety, and patient satisfaction following foam sclerotherapy for varicose veins. There have been 60 cases with lower limb varicosities whose mean age was 33.72 years (range, $20-52$ ). Females represented $62 \%$ of cases, while the remaining cases were males. As regards the duration of varicosities during this study, it had a mean of 6.03 years (range, $1-12$ ). The right leg was affected in $52 \%$ of cases, while the other cases had the left side affected. The large saphenous veins were treated with 3\% Aethoxysclerol. Accessory great saphenous and short saphenous veins were treated with $2 \%$ Aethoxysclerol. Reticular veins and telangiectasia treated with $1 \%$ Aethoxysclerol
\end{abstract}

Results: The cosmetic appearance showed a major improvement ( $p<0.001)$ after our intervention. Pain sensation was significantly decreased after the intervention. Only $25 \%$ of cases reported that sensation after 1 week, which percent decreased all the way down to 3, 3, and seven during the following visits respectively. Saphenofemoral reflux was present in $48 \%$ of cases before the intervention, and it decreased all the way down to 7, 3, 3, and seven of cases at the scheduled follow-up visits respectively. Complications were reported by $28 \%$ of cases, Skin hyperpigmentation was the most common complication (22\%), followed by visual disturbances (8\%), and thrombophlebitis $(7 \%)$.

Conclusion: Ultrasound-guided foam sclerotherapy seemed to be a safe and effective procedure for the treatment of chronic venous insufficiency within the selected group of patients.

Keywords: Ultrasound-guided foam sclerotherapy, Superficial venous reflux, Radiofrequency ablation \& Clinical, Etiological, Anatomical, and Pathophysiological(CEAP). 


\section{Introduction}

Varicose veins are elongated, tortuous, and dilated lower-limb superficial veins with faulty valves. Varicose veins are described by the World Health Organization (WHO) as saccular dilatation of the veins, which are sometimes tortuous. [1]. Varicose veins are divided into primary and secondary varicose veins according to their etiology. Secondary varicose veins nearly always occur as a result of a change within the deep venous system's operation, whether it's an outflow obstruction, pump failure, or a mixture of the two. Primary varicose veins are caused by a variety of things that are unknown. [2]. Sclerotherapy may be a minimally invasive technique that uses an injection of a special chemical (sclerosant) into a venous blood vessel to break and scar the linin$\mathrm{g}$ of the vein. Resulting in blockage of the treated venous blood vessel [3].

The results with foam sclerotherapy are excellent and this method of treatment offers a good alternative to surgery [4]. Ultrasound-guided foam scleratherapy (UGFS) is effective for every kind of pathological venous dilatation from major truncal varicose veins to the smallest telangiectasias [5]. UGFS is widely employed in most countries to eradicate superficial venous reflux (SVR). UGFS ends up in significant improvements in symptoms and venous hemodynamics and is additionally related to high levels of patient satisfaction [6]. Ultrasound is useful in guiding the injection of foamed sclerosants. Foam is extremely visible with ultrasound, allowing for a more accurate injection. It also enables immediate post-injection observation of vein compressibility as a predictor of treatment efficacy [1]. Foam sclerotherapy has potential benefits over other standard treatments for varicose veins like surgery and endovascular interventions. Surgery carries a risk of anesthesia and therefore the time of work of [2]. Most complications fr- om sclerotherapy are minor and transient. They include hyperpigmentation, $\mathrm{p}$ ain, and urticaria [8]. This study was done to explain the efficacy and safety of foam sclerotherapy within

the treatment of varicose veins and to see patient's satisfaction after UGFS for Varicose veins in terms of improvement in appearance, beneficial effect on lifestyle, and relief of symptoms.

\section{Patients and Methods}

This Prospective cohort study was done at the Radiology Department, Faculty of Medicine, Sohag University, and included 60 patients over 2 years (from October 2018 to September 2020).

The study included Patients with primary symptomatic varicosities due to great saphenous vein (GSV) reflux and/or lesser saphenous vein (LSV) reflux and/or incompetent perforators, Patients with varicosities related to isolated refluxing accessory saphenous veins or tributaries, and Patients with reticular vein and/or telangiectasia, and excluded patients with Pregnancy, Malignancy, coagulopathy, Breastfeeding, Recent or old DVT, Peripheral arterial disease, Known allergy to sclerosant material (Aethoxysclerol) and Lack of mobility. All patients were subjected to the Full history taking and clinical examination, and they were informed about the ultrasound-guided foam scleratherapy technique, they had Pretreatment Doppler scanning to identify sites of superficial venous reflux and incompetent perforators and to exclude possible DVT or phlebitis, the long course of refluxing vein is marked by ultrasound guidance, they were treated by ultrasound-guided foam sclerotherapy: The target vein cannulated under ultrasound guidance with an intravenous cannula or butterfly needle 18,20 , or $22 \mathrm{G}$ at multiple levels, Foam generated using Tessari method (This method includes mixing one part of the commercially 
SOHAG MEDICAL JOURNAL Vol. 25 No. 3 July 2021 available sclerosant, Aethoxysclerol 1$3 \%$, with four parts of air using two syringes and a three-way tap. Great saphenous vein treated with 3\% Aethoxysclerol. Accessory great saphenous and short saphenous veins treated with $2 \%$ Aethoxysclerol. Reticular veins and telangiectasia treated by $1 \%$ Aethoxysclerol), after cannulation, the limb is elevated prior to injection of foam then We manually compressed the saphenofemoral junction during injection into the GSV, the development of vasospasm in the target vein and the detection that the vein was completely filled by foam was used to judge satisfactory completion of the therapy session, then the Patients were asked to actively dorsiflex and plantarflex the ankle to maintain deep venous blood flow after each injection. Instructions given for patient immediately post-procedure: to walk for at least half-hour. To have plenty of fluids. To maintain external compression for 4 days. The anti-inflammatory medication was prescribed. Early follow-up 1-3 days post-injection and long follow-up to 6 months (by clinical examination and Doppler study).

Table (1): Criteria for successful and unsuccessful treatment:

\begin{tabular}{|c|c|c|}
\hline & Post-treatment successful criteria & $\begin{array}{l}\text { Post-treatment unsuccessful } \\
\text { criteria }\end{array}$ \\
\hline Doppler examination & $\begin{array}{l}\text { - No reflux } \\
\text { - Complete disappearance of treated } \\
\text { vein or becoming fibrous cord or total } \\
\text { occlusion (non-compressibility) of } \\
\text { the treated venous segment. }\end{array}$ & $\begin{array}{l}\text { - Reflux }>1 \text { second or } \\
\text { unchanged. } \\
\text { - Complete (or incomplete) } \\
\text { patency and/or diameter } \\
\text { unchanged. }\end{array}$ \\
\hline Clinically & No visible varicose veins. & $\begin{array}{l}\text { No significant change or } \\
\text { worsen (i.e., varicose veins } \\
\text { became larger and more } \\
\text { visible). }\end{array}$ \\
\hline symptoms & $\begin{array}{l}\text { Confirmed absent or improved } \\
\text { symptoms. }\end{array}$ & $\begin{array}{l}\text { confirmed No change or worse } \\
\text { symptoms }\end{array}$ \\
\hline
\end{tabular}

\section{Statistical analysis}

IBM's SPSS statistics were used for optimum statistical analysis of the collected data. Shapiro-Wilk test was used to examine the normality of the distribution of data. All tests were conducted with a $95 \%$ confidence interval. P-value $<0.05$ was considered statistically significant. End-intervention questionnaire: The patients were asked to grade the improvement that they will experience in terms of symptoms, cosmoses and lifestyle.

Ethical considerations written informed consent obtained from each patient. The study was approved by the ethics committee of the Faculty of Medicine, Sohag University.

\section{Results:}

In this study, there were $\mathbf{6 0}$ patients included and were divided into 23 males $(38 \%)$ and 37 females $(62 \%)$, the average age in this study was 33.72 years \pm Standard deviation (SD) 6.87, the youngest was 20 years and the oldest was 52 years. The right side was affected in 31 patients $(52 \%)$ while the left side was affected in 29 patients (48\%). The average duration of the disease was 6.03 years \pm SD 3.04, the least duration of the disease was one year, and the maximum was 12 years. Pre and post-treatment assessment of bad cosmoses was done to the 60 patients, the bad cosmesis was still found in 35 patients $(58 \%)$ after one week, in 10 patients $(17 \%)$ after one month, in 4 patients $(7 \%)$ after 3 months 
SOHAG MEDICAL JOURNAL Vol. 25 No. 3 July 2021 and in 6 patients $(10 \%)$ after 6 months after receiving the treatment. These variations showed statistically significant differences after one week, one month, 3 months, and after 6 months on the bad cosmesis after receiving treatment $(\mathrm{P}<0.001)$, so the treatment had an obvious effect on decreasing bad cosmesis (table 2).

Table (2): Pre- and post-treatment assessment of bad cosmesis in the studied patients:

\begin{tabular}{|l|l|l|}
\hline Bad cosmesis & $\begin{array}{l}\text { All patients } \\
(\mathrm{n}=60)\end{array}$ & $\mathrm{p}$ \\
\hline Basal & $100 \%(60)$ & - \\
\hline One week & $58 \%(35)$ & $<\mathbf{0 . 0 0 1}$ \\
\hline One month & $17 \%(10)$ & $<\mathbf{0 . 0 0 1}$ \\
\hline Three months & $7 \%(4)$ & $<\mathbf{0 . 0 0 1}$ \\
\hline Six months & $10 \%(6)$ & $<\mathbf{0 . 0 0 1}$ \\
\hline
\end{tabular}

Pre and post-treatment assessment of pain was done to 52 patients and the pain was still present in 22 patients (37\%) after one week, in 2 patients (3\%) after one month, in 2 patients $(3 \%)$ after 3 months, and in 4 patients $(7 \%)$ after 6 months from receiving the treatment. These variations showed statistically significant differences after one week, one month, 3 months, and 6 months after receiving the treatment on the severity of the pain $(\mathrm{P}<0.001)$, so the treatment had an obvious effect on decreasing the pain (table 3 ).

Table (3): Pre- and post-treatment assessment of pain in the studied patients:

\begin{tabular}{|l|l|l|}
\hline Pain & $\begin{array}{l}\text { All patients } \\
(\mathrm{n}=60)\end{array}$ & $\mathrm{p}$ \\
\hline Basal & $87 \%(52)$ & - \\
\hline One week & $37 \%(22)$ & $<\mathbf{0 . 0 0 1}$ \\
\hline One month & $3 \%(2)$ & $<\mathbf{0 . 0 0 1}$ \\
\hline Three months & $3 \%(2)$ & $<\mathbf{0 . 0 0 1}$ \\
\hline Six months & $7 \%(4)$ & $<\mathbf{0 . 0 0 1}$ \\
\hline
\end{tabular}

The average number of sessions done to all patients in this study was $1.67 \pm$ SD0.752, the minimum number of sessions was one session and the maximum was 3 sessions, the average volume of injected foam was $11.33 \mathrm{ml}$ \pm SD 4.011, the minimum injected amount was $5 \mathrm{ml}$ and the maximum was 22 , the average concentration of Aestheox1sklerol was $0.02 \pm$ SD 0.006 , the minimum concentration was 0.01 and the maximum was 0.03 . The 60 patients were classified according to ClinicalEtiological-Anatomical-Pathophysiological (CEAP) classification; there were 7 patients $(12 \%) \mathrm{C}-1,42$ patients (70\%) C-2, 7 patients (12\%) C-3, one patient $(2 \%) \mathrm{C}-4$, one patient $(2 \%) \mathrm{C}-5$ and 2 patients $(3 \%)$ C-6 (Table 4$)$.

Table (4): number of sessions, volume and concentration of injection, and CEAP classification of the studied patients:

\begin{tabular}{|c|c|c|c|c|c|c|}
\hline & \multicolumn{5}{|c|}{ All patients $(n=60)$} \\
\hline & & Mean \& SD & Median & Minimum & Maximum & IQR \\
\hline \multicolumn{2}{|c|}{ Number of sessions } & $1.67 \pm 0.752$ & 1.50 & 1.00 & 3.00 & $1.00,2.00$ \\
\hline \multicolumn{2}{|c|}{ volume of injected foam (ml) } & $11.33 \pm 4.011$ & 10.00 & 5.00 & 22.00 & $9.00,14.00$ \\
\hline \multicolumn{2}{|c|}{$\begin{array}{l}\text { concentration } \\
\text { Aestheox1sklerol }\end{array}$} & $0.02 \pm 0.006$ & 0.02 & 0.01 & 0.03 & $0.02,0.03$ \\
\hline \multirow[t]{6}{*}{ CEAP } & 1 & \multicolumn{5}{|l|}{$12 \%(7)$} \\
\hline & 2 & \multicolumn{5}{|l|}{$70 \%(42)$} \\
\hline & 3 & \multicolumn{5}{|l|}{$12 \%(7)$} \\
\hline & 4 & \multicolumn{5}{|l|}{$2 \%(1)$} \\
\hline & 5 & \multicolumn{5}{|l|}{$2 \%(1)$} \\
\hline & 6 & \multicolumn{5}{|l|}{$3 \%(2)$} \\
\hline
\end{tabular}


SOHAG MEDICAL JOURNAL

Vol. 25 No. 3 July 2021
Pre and post-treatment assessment of

\section{Long saphenous vein reflux}

was done to 29 patients (48\%), the reflux was still found in 6 patients (10\%) after one wee-k, in 2 patients (3\%) after one month, in 2 patients $(3 \%)$ after 3 months and in 4 patients $(7 \%)$ after 6 months from recei-ving the treatment. These variations sh-owed statistically significant differences after one week, one month, 3 months, and after 6 months after the Long saphenous vein reflux after receiving treatment $(\mathrm{P}<0.0$ 01 ), so the treatment had an obvious effect on decreasing the Long saphenous vein reflux (Table 7).

Table (5): Pre- and post-treatment assessment of long saphenous vein reflux in the studied patients:

\begin{tabular}{|l|l|l|}
\hline $\begin{array}{l}\text { Long } \\
\text { saphenous vein } \\
\text { reflux }\end{array}$ & $\begin{array}{l}\text { All patients } \\
(\mathrm{n}=60)\end{array}$ & $\mathrm{P}$ \\
\hline Basal & $48 \%(29)$ & - \\
\hline One week & $10 \%(6)$ & $<\mathbf{0 . 0 0 1}$ \\
\hline One month & $3 \%(2)$ & $<\mathbf{0 . 0 0 1}$ \\
\hline Three months & $3 \%(2)$ & $<\mathbf{0 . 0 0 1}$ \\
\hline Six months & $7 \%(4)$ & $<\mathbf{0 . 0 0 1}$ \\
\hline
\end{tabular}

Pre and post-treatment assessment of

\section{short saphenous vein reflux}

was done to 8 patients (13\%), the reflux was found neither after one week nor after one month, 3 months, and 6 months from receiving the treatment. These variations showed statistically significant differences after one week, one month, 3 months, and after 6 months on the short saphenous vein reflux after receiving treatment $(\mathrm{P}<0.01)$, so the treatment had an obvious effect on decreaseng the short saphenous vein reflux (Table 8).
Table (6): Pre- and post-treatment assessment of short saphenous vein reflux in the studied patients:

\begin{tabular}{|l|l|l|}
\hline $\begin{array}{l}\text { Short saphenous } \\
\text { vein reflux }\end{array}$ & $\begin{array}{l}\text { All patients } \\
(\mathrm{n}=60)\end{array}$ & $\mathrm{p}$ \\
\hline Basal & $13 \%(8)$ & - \\
\hline One week & $0 \%(0)$ & $\mathbf{0 . 0 0 8}$ \\
\hline One month & $0 \%(0)$ & $\mathbf{0 . 0 0 8}$ \\
\hline Three months & $0 \%(0)$ & $\mathbf{0 . 0 0 8}$ \\
\hline Six months & $0 \%(0)$ & $\mathbf{0 . 0 0 8}$ \\
\hline
\end{tabular}

Pre and post-treatment assessment of

posterior accessory saphenous vein (PASV) reflux was done to 8 patients $(13 \%)$, the reflux was found in 2 patients $(3 \%)$ after one week of treatment, but after one month, 3 months, and 6 months from receiving the treatment there were no cases with PASV reflux. These variations showed statistically significant differences after one week, one month, 3 months, or 6 months on the PASV reflux after receiving the treatment $(\mathrm{P}<0.01)$, so the treatment had an obvious effect on decreasing the PASV reflux (Table 7).

Table (7): Pre- and post-treatment assessment of PASV reflux in the studied patients:

\begin{tabular}{|l|l|l|}
\hline APSV reflux & $\begin{array}{l}\text { All patients } \\
(\mathrm{n}=60)\end{array}$ & $\mathrm{p}$ \\
\hline Basal & $13 \%(8)$ & - \\
\hline One week & $3 \%(2)$ & $\mathbf{0 . 0 3 1}$ \\
\hline One month & $0 \%(0)$ & $\mathbf{0 . 0 0 8}$ \\
\hline Three months & $0 \%(0)$ & $\mathbf{0 . 0 0 8}$ \\
\hline Six months & $0 \%(0)$ & $\mathbf{0 . 0 0 8}$ \\
\hline
\end{tabular}

Pre and post-treatment assessment of

telangiectasia was done to 9 patients $(15 \%)$, the telangiectasia was still found in 5 patients $(8 \%)$ after one week of treatment, but after one month, 3 months, and 6 months from receiving the treatment there were no cases with telangiectasia. 
SOHAG MEDICAL JOURNAL Vol. 25 No. 3 July 2021

These variations showed statisti-cally significant differences after one month, 3 months, or 6 months on the telangiectasia after receiving the treatment $(\mathrm{P}<0.05)$ but not after one week of receiving the treatment $(\mathrm{P}>0.05)$, so the treatment had an obvious effect on decreasing the telangiectasia (table 8).

Table (8): Pre- and post-treatment assessment of telangiectasia in the studied patients:

\begin{tabular}{|l|l|l|}
\hline Telangiectasia & $\begin{array}{l}\text { All patients } \\
(\mathrm{n}=60)\end{array}$ & $\mathrm{p}$ \\
\hline Basal & $15 \%(9)$ & - \\
\hline One week & $8 \%(5)$ & 0.125 \\
\hline One month & $0 \%(0)$ & $\mathbf{0 . 0 0 4}$ \\
\hline Three months & $0 \%(0)$ & $\mathbf{0 . 0 0 4}$ \\
\hline Six months & $0 \%(0)$ & $\mathbf{0 . 0 0 4}$ \\
\hline
\end{tabular}

Pre and post-treatment assessment of

venous ulcer was done to 3 patients $(5 \%)$, the ulcer was still found in 3 patients $(5 \%)$ after one week and also after one month from receiving the treatment but not after 3 months and 6 months from receiving the treatment. These variations did not show any statistically significant differences after one week, one month, 3 months, or 6 months on the venous ulcer after receiving treatment $(\mathrm{P}>0.05)$ due to the small number of patients affected (table 9 ).

Table (9): Pre- and post-treatment assessment of venous ulcer in the studied patients:

\begin{tabular}{|l|l|l|}
\hline Venous ulcer & $\begin{array}{l}\text { All patients } \\
(\mathrm{n}=60)\end{array}$ & $\mathrm{p}$ \\
\hline Basal & $5 \%(3)$ & - \\
\hline One week & $5 \%(3)$ & 1.000 \\
\hline One month & $5 \%(3)$ & 1.000 \\
\hline Three months & $0 \%(0)$ & 0.250 \\
\hline Six months & $0 \%(0)$ & 0.250 \\
\hline
\end{tabular}

Pre and post-treatment assessment of incompetent perforators was done to the 60 patients $(100 \%)$, there were 35 patients $(58 \%)$ who had no perforators, 10 patients $(17 \%)$ had one perforator, 12 patients $(20 \%)$ had 2 perforators, 3 patients $(2 \%)$ had 3 perforators. After receiving the treatment, incompetent perforators were assessed there were 58 patients $(97 \%)$ who had no incompetent perforators after one week, one month, 3 months, and six months from receiving the treatment, and 2 patients $(3 \%)$ had just one incompetent perforator after one week, one month, 3 months and six months from receiving the treatment. These variations showed statistically significant differences after one week, one month, 3 months, and 6 months on the incompetent perforators after receiving treatment $(\mathrm{P}<0.01)$, so the treatment had an obvious effect on decreasing the incompetent perforators (table 10)

Table (10): Pre- and post-treatment assessment of incompetent perforators in the studied patients

\begin{tabular}{|c|c|c|c|}
\hline \multicolumn{2}{|c|}{$\begin{array}{l}\text { Incompetent } \\
\text { perforators }\end{array}$} & $\begin{array}{l}\text { All } \\
\text { patients } \\
(n=60)\end{array}$ & $\mathrm{P}$ \\
\hline \multirow[t]{4}{*}{ Basal } & 0 & $58 \%(35)$ & \multirow[t]{4}{*}{-} \\
\hline & 1 & $17 \%(10)$ & \\
\hline & 2 & $20 \%(12)$ & \\
\hline & 3 & $5 \%(3)$ & \\
\hline \multirow[t]{2}{*}{ One week } & $\mathbf{0}$ & $97 \%(58)$ & \multirow[t]{2}{*}{$<0.001$} \\
\hline & 1 & $3 \%(2)$ & \\
\hline \multirow{2}{*}{$\begin{array}{l}\text { One } \\
\text { month }\end{array}$} & $\mathbf{0}$ & $97 \%(58)$ & \multirow[t]{2}{*}{$<0.001$} \\
\hline & 1 & $3 \%(2)$ & \\
\hline \multirow{2}{*}{$\begin{array}{l}\text { Three } \\
\text { months }\end{array}$} & $\mathbf{0}$ & $97 \%(58)$ & \multirow[t]{2}{*}{$<0.001$} \\
\hline & 1 & $3 \%(2)$ & \\
\hline \multirow{2}{*}{$\begin{array}{l}\text { Six } \\
\text { months }\end{array}$} & $\mathbf{0}$ & $97 \%(58)$ & \multirow[t]{2}{*}{$<0.001$} \\
\hline & 1 & $3 \%(2)$ & \\
\hline
\end{tabular}

Post-treatment complications were assessed in this study and there were 17 patients $(28 \%)$ who had complications, 13 patients (22\%) had Skin Hyperpigmentation, 4 patients (7\%) had Thrombo- 
SOHAG MEDICAL JOURNAL

Vol. 25 No. 3 July 2021 phlebitis and 5 patients ( $8 \%$ ) had Visual disturbance. But no cases had neither DVT, Stroke, Migraine nor Skin necrosis (Table 11).

Table (11): post-treatment complications in the studied patients:

\begin{tabular}{|l|l|}
\hline & $\begin{array}{l}\text { All patients } \\
(\mathrm{n}=60)\end{array}$ \\
\hline Complications & $28 \%(17)$ \\
\hline Skin Hyperpigmentation & $22 \%(13)$ \\
\hline Thrombophlebitis & $7 \%(4)$ \\
\hline DVT & $0 \%(0)$ \\
\hline Visual disturbance & $8 \%(5)$ \\
\hline Stroke & $0 \%(0)$ \\
\hline Migraine & $0 \%(0)$ \\
\hline Skin necrosis & $0 \%(0)$ \\
\hline
\end{tabular}

\section{Case presentation}

Female patient 35 years old, had right visible varicosities and pain for 3 years,
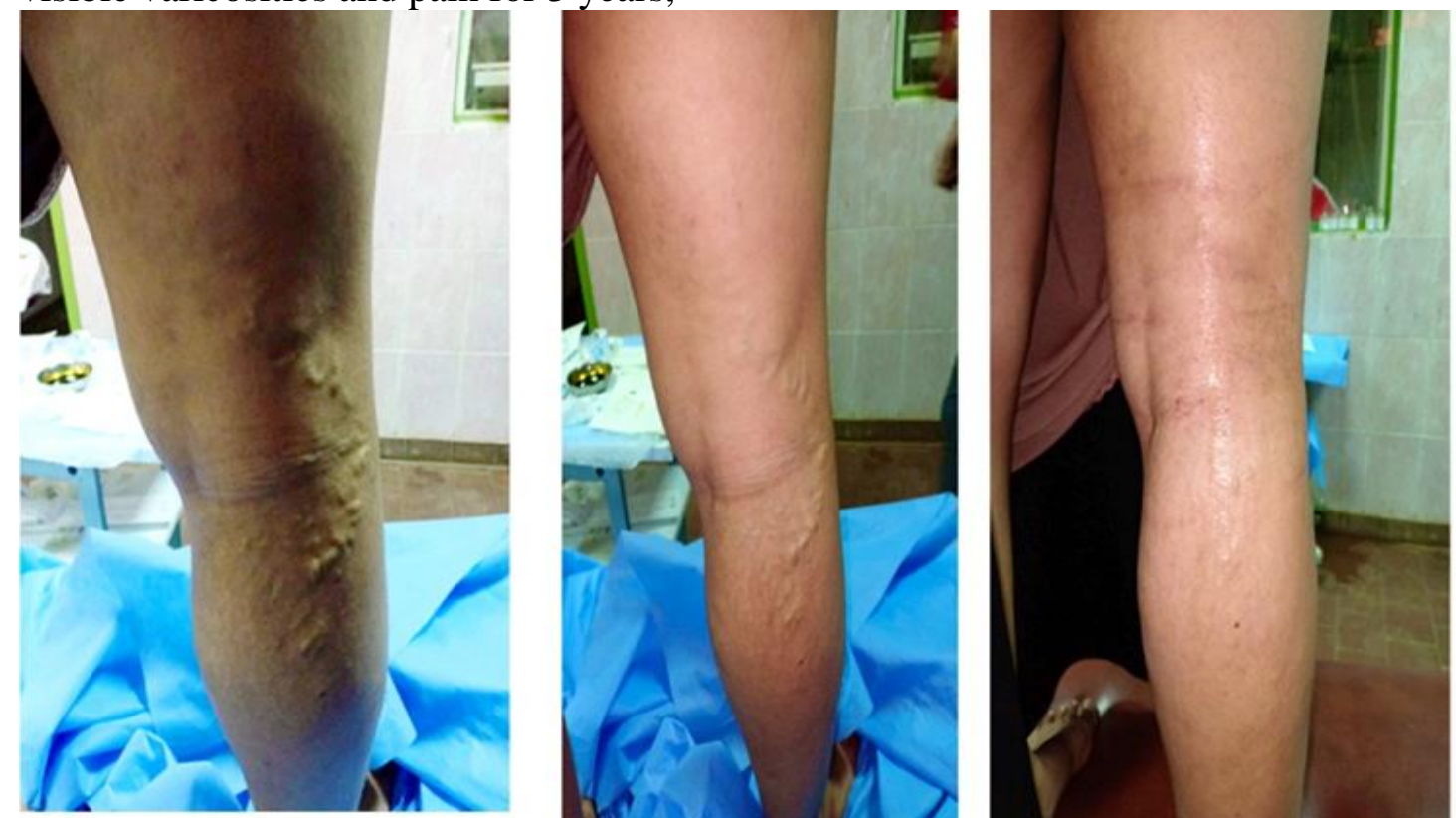

Figure (1): the stated case shows (A) visible subcutaneous varicosities at the posterior aspect of the leg and thigh. (B) After one session of UGFS. (C) After two sessions of UGFS, the total disappearance of varicosities. (D) Ultrasound examination revealed total occlusion of the vessel without any signs of revascularization.

\section{Discussion}

Chronic venous insufficiency could be a quite common medical problem Surgical therapy remains the first treatment option at all stages of the disease above clinical state C1. Surgery has never been required - for telangiectasias. its CEAP classification was C2 Ep As Pr, her Doppler findings showed Evidence of refluxing posterior accessory saphenous vein with related subcutaneous varicosities. Two incompetent perforators are also seen. Her treatment was UGFS that was done for refluxing vein and two incompetent perforators, through 2 sessions. The volume of injected foam (ml) was $15 \mathrm{ml}$ and the concentration of Aestheoxysklerol was 2\%. Her Post-treatment assessment showed the complete disappearance of a treated vei$\mathrm{n}$ and incompetent perforators. Nearly No visible varicosities could be detected. The patient satisfaction was excelent and there were no complications. 
classification, location of this lesion, cost of the treatment, complaints, concomitant diseases, and obesity, willingness to resume work, prejudice against some methods of treatment or their complications, etc. ${ }^{[10]}$ Rasmussen et al. in their investigation comparing UGFS, radiofrequency ablation (RFA), endovenous laser ablation (EVLA), and surgery reported the highest recurrence of reflux in treated GSVs 1 year after foam sclerotherapy. These authors however recognized this method as the least traumatic, the most affordable, and straightforward to repeat. ${ }^{[1]}$ The treatment itself is comparatively easy to perform, effortless, and may be conducted in an outpatient clinic. ${ }^{[12]}$ This study was conducted at Sohag University Hospitals planning to evaluate the efficacy, safety, and patient satisfaction following foam sclerotherapy for varicose veins. We included a complete of $60 \mathrm{ca}$ ses with lower limb varicosities whose mean age was 33.72 years (range, $20-$ 52). Another study hand-ling the identical perspective included a complete of 52 cases with GSV incompetence and with or without concomitant varicose veins were treated with US-guided foam sclerotherapy. The mean age was 54 (from 30 to 65 ) years. ${ }^{[13]}$

Within the current study, females represented $62 \%$ of cases, while the remaining cases were males. Another study also reported female predominance. Authors included 46 (88.5\%) females and $6(11.5 \%)$ male patients. ${ }^{[13]}$ This was further confirmed by another study which reported that $82 \%$ of the included cases were females. ${ }^{[14]}$ Conversely, another study reported a high predominance of males, as they represented $74 \%$ of the study cases. ${ }^{[15]}$ Regarding CEAP classification, class 2 was the m-ost common class encountered (42 cas-es $70 \%$ ), followed by class 1 and three (12\% for each), class $6(3 \%)$, whereas class 4 and 5 were present in $2 \%$ of cases for every. In another study, CEAP classification was as follows; class 2 $(9.52 \%)$, class $3(36.51 \%)$, class 4 $(46.03 \%)$, and class 5 (7.94\%). ${ }^{[17]}$

The cosmetic appearance showed a significant improvement $(\mathrm{p}<0.001)$ after our intervention. All cases reported bad cosmoses before the intervention, which decreased down to $58,17,7$, and $10 \%$ at 1-week, 1-, 3-, 6-month followup visits respectively. Although there was a small rise at the 6-month visit, it was also significantly better than the basal value.

In the current study, most symptoms showed a significant improvement compared to the baseline values during the scheduled follow-up visits. Moreover, edema showed significant improvement 1 month after intervention, and that improvement was also noticed through the following visits. Unlike the other complaints, it did not show significant change after 1 week $(p=0.06)$. This could be explained by the occurrence of postprocedural inflammation and tissue response which may delay the resolution of the preexisting edema.

In another study, the majority of patients $(96 \%)$ reported an improvement in symptoms. In a semi-quantitative fashion, $33(66 \%)$ patients reported $>50 \%$ improvement, while 15 (30\%) patients reported $<50 \%$ amelioration. Only two patients felt that the procedure provided no benefit. ${ }^{[19]}$

Another study reported that there was a significant improvement in the Aberdeen Varicose Vein Symptom Severity Score as it decreased from 18.9 down to 9.7 after long-term follow-up [20]. In another study, improvements in symptoms and quality of life were $100 \% .^{[15]}$ In terms of expectations, one study shows that exceeded $25 \%$ while unmet in $10 \% .{ }^{[18]}$ Regarding patient satisfaction, it was subjectively categorized in a previous study as 'excellent, 'good', 'average' and 'poor'. 14 (28\%) patients considered foam sclerotherapy to be an excellent treatment, while 27 (54\%) de- 
cided it was good, and nine (18\%) patients subjectively confirmed the procedure to be average. No patient thought that it was a poor intervention. ${ }^{[19]}$ Furthermore, other authors reported that assessment of patients' satisfaction demonstrated that $94.4 \%$ reported satisfaction with the treatment outcomes, $88.9 \%$ stated that they would undergo the procedure again if necessary, and $77.8 \%$ said that they would recommend the treatment to a friend. ${ }^{[16]}$ As regard venous reflux in the short saphenous vein in our study, it was present in $13 \%$ of cases before the intervention, and it was not detected in any of the included cases after the intervention $(0 \%-\mathrm{p}<$ 0.001). Furthermore, large saphenous reflux was present in $48 \%$ of cases before the intervention, and its incidence decreased down to $10 \%$ after 1 week. The following visits also showed a significant decrease dow-n to 3, 3, and $7 \%$ respectively ( $p<0.001$ ). Furthermore, Saphenofemoral reflux was present in $48 \%$ of cases before the intervention, and it decreased down to 7, 3, 3, and 7\% of cases at the scheduled follow-up visits respectively $(p<0.001)$. On the other hand, although saphenopopliteal reflux disappeared after the intervention, that improvement was statistically insignificant $(p=0.008)$. As regard venous ulcer improvement, it didn't show a major change within the current study ( $p>0.05$ ). Nevertheless, it had been present in $5 \%$ of cases before the intervention, while it absolutely was absent after 3 months. In another study, the assessment of the patient's presenting venous ulcers because the main complaint (10 cases) demonstrated that upon the primary follow-up, 7 were completely healed, 2 presented improvement although hearing wasn't - complete, and 1 healed but presented recurrence. Thus, the venous ulcers reepithelialization rate was $70 \%$, with $30 \%$ presenting recurrence or improvement without complete reepithelialization.
[16] O'Hare reported a $91.2 \%$ rate of healing in 24 weeks, ${ }^{[23]}$ Kulkarni $71.1 \%$ in 24 weeks, ${ }^{[24]}$ and Cam-pos $91.3 \%$ after one year. ${ }^{[25]}$

Incompetent perforators showed a major decrease after intervention ( $\mathrm{p}<$ 0.001). It had been absent in $97 \%$ after the intervention. Although the reticular vein did show any significant improvement after intervention ( $p>0.05)$, the prevalence of telangiectasia decreased significantly from $15 \%$ before the intervention, all the way down to $0 \%$ after 1 month $(\mathrm{p}=0.004)$.

In a previous study, treatment was more likely to be effective for great saphenous compared to small saphenous veins. ${ }^{[14]}$ Others have reported better outcomes for small compared to large diameter veins ${ }^{[26,27]}$ although satisfactory results for giant veins have also been reported. ${ }^{[3,28]}$ In another study, Dopp-ler examination follow-up showed complete occlusion of the treated vein following $79 \%$ of procedures $(n=100)$. Partial occlusion of the treated vein was evident following $14 \%$ of procedures $(n=$ 18 ) and a patent treated vein was seen after $6 \%$ of procedures $(n=8)$. ${ }^{[17]}$

In another study, 177 patients with varicose veins, who were recruited from 3 different practices in Italy, were accustomed assess the efficacy and safety of ultrasound-guided foam sclerotherapy. Complete obliteration of the treated vein was detected in $161(91 \%)$ patients at 1 month. This percentage was diminished to $67 \%$ between 66 patients who had another follow-up visit at 138 (mean) days. ${ }^{\text {[29] }}$

Rabe et al. reported occlusion of great saphenous vein 3 months after sclerotherapy in $70 \%$ of cases ${ }^{[30],}$ whereas Bountouroglou et al. noted success in $87 \%$ [31]. Both authors used 3\% foamy polidocanol for sclerotherapy. consistent with Gonzalez-Zeh et al. and Figueiredo et al., patent Great saphenous vein 6 months after foam sclerotherapy was detected in $11.3 \%$ and $22 \%$ respectively 
[32, 33]. When it involves complicatio-ns encountered in our study, it had bee$\mathrm{n}$ reported by $28 \%$ of cases. Skin hyperpigmentation was the most common complication (13 cases $-22 \%$ ), followed by visual disturbances ( 5 cases $-8 \%$ ), and thrombophlebitis ( 4 cases $-7 \%$ ).

Regarding complications in other studies, six $(11.5 \%)$ patients felt moderate pain at the location of injection as it $\mathrm{w}-$ as administered. every week and a month after sclerotherapy thrombophlebitis of a part of the treated vein or its tributaries were present in $11(21 \%)$ cases. During follow-up, hyperpigmentation, which disappears with time, was detected on the skin of the thigh or calf in $9(17 \%)$ cases. Serious complications like DVT, embolism (PE), yspnea, anaphylaxis, or neurological abnormalities (vision disorders, vertigo, and loss of consciousness, stroke, or transient ischemic attacks) weren't recorded. ${ }^{[13]}$

Limitations of the studyFirst of all, it's a single-center study. Besides, it included a comparatively small sample size. Additionally, it's not a comparative study. These considerations should be kept in consideration in performing future studies.

\section{Conclusion}

Ultrasound-guided foam sclerotherapy appeared to be a safe and effective procedure for the treatment of chronic venous insufficiency in the selected group of patients. The complications were simple and most of the patients reported good satisfaction with the therapy outcomes.

\section{References}

1. Tan V. K. M., Abidin S. Z., Tan S. G. Medium-term results of ultrasonography-guided, catheterassisted foam sclerotherapy of the long saphenous vein for treatment of varicose veins. Singapore medical journal. 2012;53(2):91.
2. Rasmussen L. H., Lawaetz M., Bjoern L., Vennits B., Blemings A., Eklof B. Randomized clinical trial comparing endovenous laser ablation, radiofrequency ablation, foam sclerotherapy and surgical stripping for great saphenous varicose veins. British Journal of Surgery. 2011;98(8):10791087.

3. Barrett J. M., Allen B., Ockelford A., Goldman M. P. Microfoam ultrasound-guided sclerotherapy treatment for varicose veins in a subgroup with diameters at the junction of $10 \mathrm{~mm}$ or greater compared with a subgroup of less than $10 \mathrm{~mm}$. Dermatologic surgery. 2004;30(11):1386-1390.

4. Geroulakos G. Foam therapy for those with varicose vein. Dermatol Surg. 2005;50:89-94.

5. Rao J., Wildemore J. K., Goldman M. P. Double-blind prospective comparative trial between foamed and liquid polidocanol and sodium tetradecyl sulfate in the treatment of varicose and telangiectatic leg veins. Dermatologic surgery. 2005;31(6):631-635.

6. Darvall K. L., Bate G. R., Silverman S. H., Adam D. J., Bradbury A. W. Medium-term results of ultrasoundguided foam sclerotherapy for small saphenous varicose veins. British Journal of Surgery: Incorporating European Journal of Surgery and Swiss Surgery. 2009;96(11):1268-1273.

7. Edwards A. G., Baynham S., Lees T., Mitchell D. C. Management of varicose veins: a survey of current practice by members of the Vascular Society of Great Britain and Ireland. The Annals of The Royal College of Surgeons of England. 2009;91(1):7780 .

8. Munavalli G. S., Weiss R. A., editors. Complications of sclerotherapy. Seminars in cutaneous medicine and surgery; 20072007. 
9. McArdle M., Hernandez-Vila E. A. Management of chronic venous disease. Texas Heart Institute Journal. 2017;44(5):347-349.

10. Chen H., Reames B., Wakefield T. W. Management of Chronic Venous Disease and Varicose Veins in the Elderly. Vascular Disease in Older Adults: Springer; 2017. p. 95-111.

11. Rasmussen L., Lawaetz M., Bjoern L., Vennits B., Blemings A., Eklof B. Randomized clinical trial comparing endovenous laser ablation, radiofrequency ablation, foam sclerotherapy and surgical stripping for great saphenous varicose veins. British Journal of Surgery. 2011;98(8):10791087.

12. Smith P. C. Chronic venous disease treated by ultrasound-guided foam sclerotherapy. European journal of vascular and endovascular surgery. 2006;32(5):577-583.

13. Kurnicki J., Osęka M., Torus R., Gałązka Z. Ultrasound-guided foam sclerotherapy of great saphenous vein with $2 \%$ polidocanol-one-year followup results. Videosurgery and Other Miniinvasive Techniques. 2016;11(2):67.

14. Myers K., Jolley D., Clough A., Kirwan J. Outcome of ultrasoundguided sclerotherapy for varicose veins: medium-term results assessed by ultrasound surveillance. European journal of vascular and endovascular surgery. 2007;33(1):116-121.

15. Maurya A. K., Singh S., Sachdeva V., Nath B., Verma S. C., Gupta P. K. Outcome of ultrasound-guided foam sclerotherapy treatment for varicose veins: the procedure is standard and need no further study. Indian Journal of Vascular and Endovascular Surgery. 2015;2(3):96.

16. Ceratti S., Okano F. M., Pontes A. B. G., Pontes A. L., Nastri R. Ultrasound-guided foam sclerotherapy in the treatment of chronic venous insufficiency. Radiol Bras. 2011;44:167-171.

17. Thomasset S., Butt Z., Liptrot S., Fairbrother B., Makhdoomi K. Ultrasound-guided foam sclerotherapy: factors associated with outcomes and complications. European Journal of Vascular and Endovascular Surgery. 2010;40(3):389-392.

18. Darvall K., Bate G., Sam R., Adam D., Silverman S., Bradbury A. Patients' expectations before and satisfaction after ultrasound-guided foam sclerotherapy for varicose veins. European Journal of Vascular and Endovascular Surgery. 2009;38(5):642-647.

19. Tan V., Abidin S., Tan S. Mediumterm results of ultrasonographyguided, catheter-assisted foam sclerotherapy of the long saphenous vein for treatment of varicose veins. Singapore medical journal. 2012;53(2):91.

20. Darvall K., Bate G., Bradbury A. Patient-reported outcomes 5-8 years after ultrasound-guided foam sclerotherapy for varicose veins. British Journal of Surgery. 2014;101(9):1098-1104.

21. Hamel-Desnos C., Desnos P., Wollmann J. C., Ouvry P., Mako S., Allaert F. A. Evaluation of the efficacy of polidocanol in the form of foam compared with liquid form in sclerotherapy of the greater saphenous vein: initial results. Dermatologic surgery. 2003;29(12):1170-1175.

22. Wright D. Varisolve European Phase III Investigators Group. Varisolve ${ }^{\wedge}($ ! R) polidocanol microfoam compared with surgery or sclerotherapy in the management of varicose veins in the presence of trunk vein incompetence: European randomized controlled trial. Phlebology. 2006;21:180-190.

23. O'Hare J., Earnshaw J. Randomised clinical trial of foam sclerotherapy for patients with a venous leg ulcer. European Journal of Vascular and 
Endovascular

2010;39(4):495-499.

Surgery.

24. Kulkarni S., Slim F., Emerson L., Davies C., Bulbulia R., Whyman M., et al. Effect of foam sclerotherapy on healing and long-term recurrence in chronic venous leg ulcers. Phlebology. 2013;28(3):140-146.

25. Campos Jr W., Torres I. O., da Silva E. S., Casella I. B., Puech-Leão P. A prospective randomized study comparing polidocanol foam sclerotherapy with surgical treatment of patients with primary chronic venous insufficiency and ulcer. Annals of vascular surgery. 2015;29(6):11281135 .

26. Myers K. A., Ziegenbein R. W., Zeng G. H., Matthews P. G. Duplex ultrasonography scanning for chronic venous disease: patterns of venous reflux. Journal of vascular surgery. 1995;21(4):605-612.

27. Tessari L., Cavezzi A., Frullini A. Preliminary experience with new sclerosing foam in the treatment of varicose veins. Dermatologic surgery. 2001;27(1):58-60.

28. Cabrera J., Cabrera Jr J., GarcíOlmedo A. Treatment of varicose long saphenous veins with sclerosant in microfoam form: long-term outcomes. Phlebology. 2000;15(1):19-23.

29. Cavezzi A., Frullini A., Ricci S., Tessari L. Treatment of varicose veins by foam sclerotherapy: two clinical series. Phlebology. 2002;17(1):13-18.

30. Rabe E., Otto J., Schliephake D., Pannier F. Efficacy and safety of great saphenous vein sclerotherapy using standardized polidocanol foam (ESAF): a randomized controlled multicentre clinical trial. European Journal of Vascular and Endovascular Surgery. 2008;35(2):238-245.

31. Bountouroglou D., Azzam M., Kakkos S., Pathmarajah M., Young
P., Geroulakos G. Ultrasound-guided foam sclerotherapy combined with saphenofemoral ligation compared to surgical treatment of varicose veins: early results of a randomized controlled trial. European journal of vascular and endovascular surgery. 2006;31(1):93100.

32. Figueiredo M., Araújo S., Barros Jr N., Miranda Jr F. Results of surgical treatment compared with ultrasoundguided foam sclerotherapy in patients with varicose veins: a prospective randomized study. European Journal of Vascular and Endovascular Surgery. 2009;38(6):758-763.

33. Gonzalez-Zeh R., Armisen R., Barahona S. Endovenous laser and echo-guided foam ablation in great saphenous vein reflux: one-year follow-up results. Journal of vascular surgery. 2008;48(4):940-946.

34. Van Neer P. A. Perforans varicosis: treatment of the incompetent perforating vein is important. Dermatologic surgery. 2004;30(5):754-755.

35. Hamel-Desnos C., Guias B., Desnos P., Mesgard A. Foam sclerotherapy of the saphenous veins: a randomized controlled trial with or without compression. European Journal of Vascular and Endovascular Surgery. 2010;39(4):500-507.

36. Hamel-Desnos C., Ouvry P., Benigni J.-P., Boitelle G., Schadeck M., Desnos P., et al. Comparison of $1 \%$ and $3 \%$ polidocanol foam in ultrasound-guided sclerotherapy of the great saphenous vein: a randomized, double-blind trial with 2-year followup."The 3/1 Study". European journal of vascular and endovascular surgery. 2007;34(6):723-729. 
SOHAG MEDICAL JOURNAL

Vol. 25 No. 3 July 2021
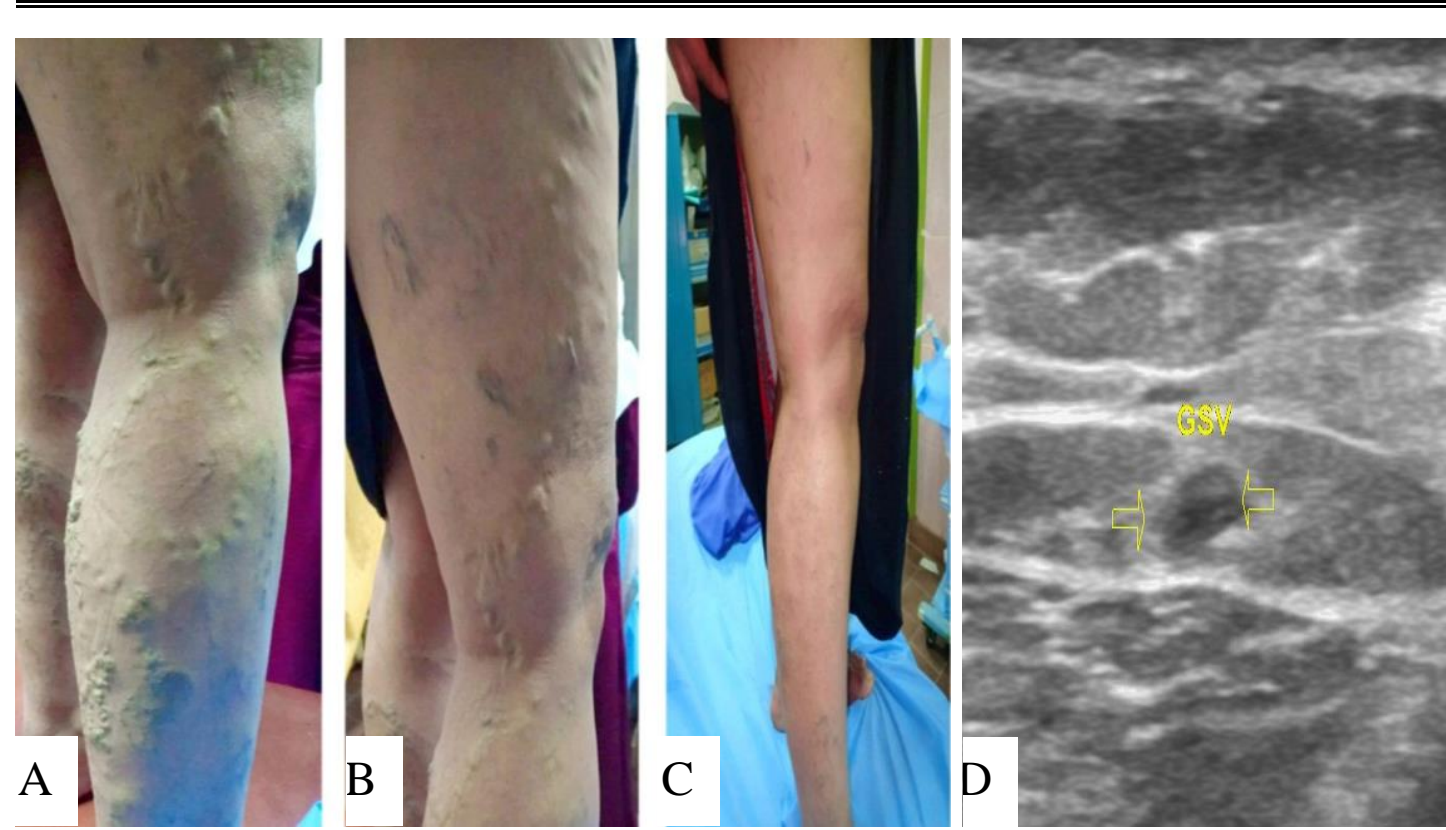

Figure(2). [33] Case no. 2: (A) (B) marked visible varicosities. (C) After three sessions of UGFS, Showing significant improvement. (D) Ultrasound study, the GSV thrombosed and noncompressible with marked reduction in diameter.
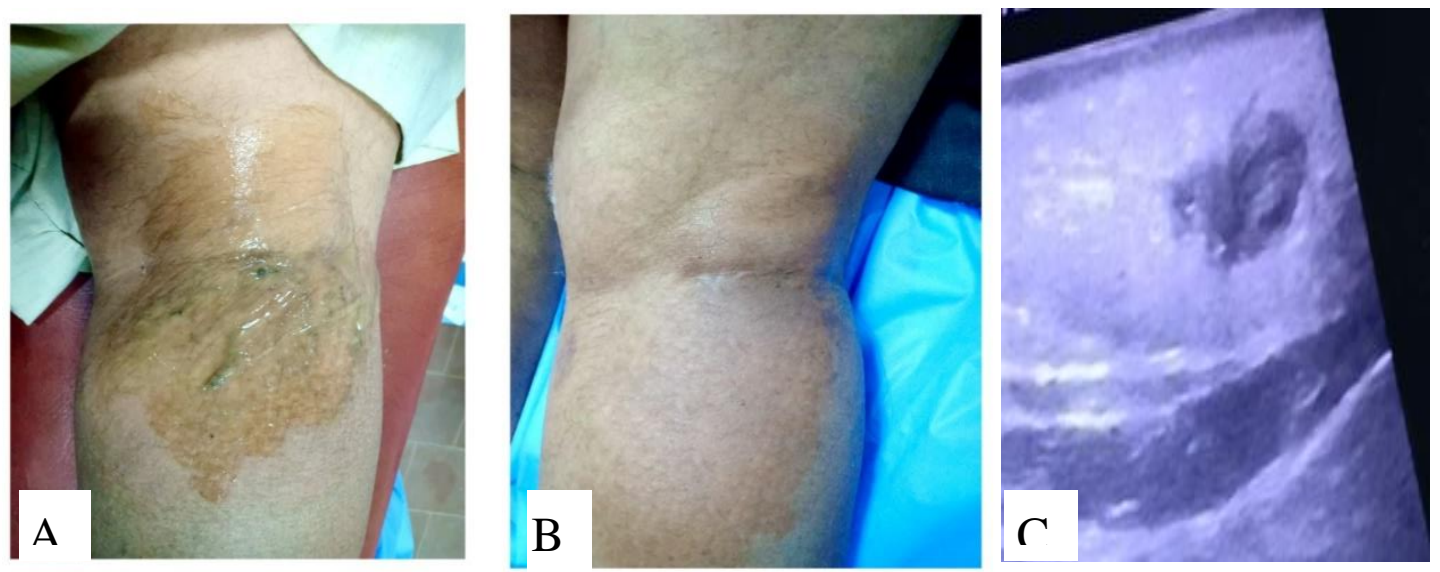

Figure(3). [35] Case no. 4: (A) subcutaneous varicosities at posterior aspect of upper leg. (B) After one session of UGFS, total disappearance of varicosities. (C) Ultrasound examination, the treated vein totally thrombosed with fibrosis changes. 
SOHAG MEDICAL JOURNAL

Vol. 25 No. 3 July 2021

Ultrasound-guided foam sclerotherapy of lower limb Waleed Araby Abd Elkhalek Elmadany
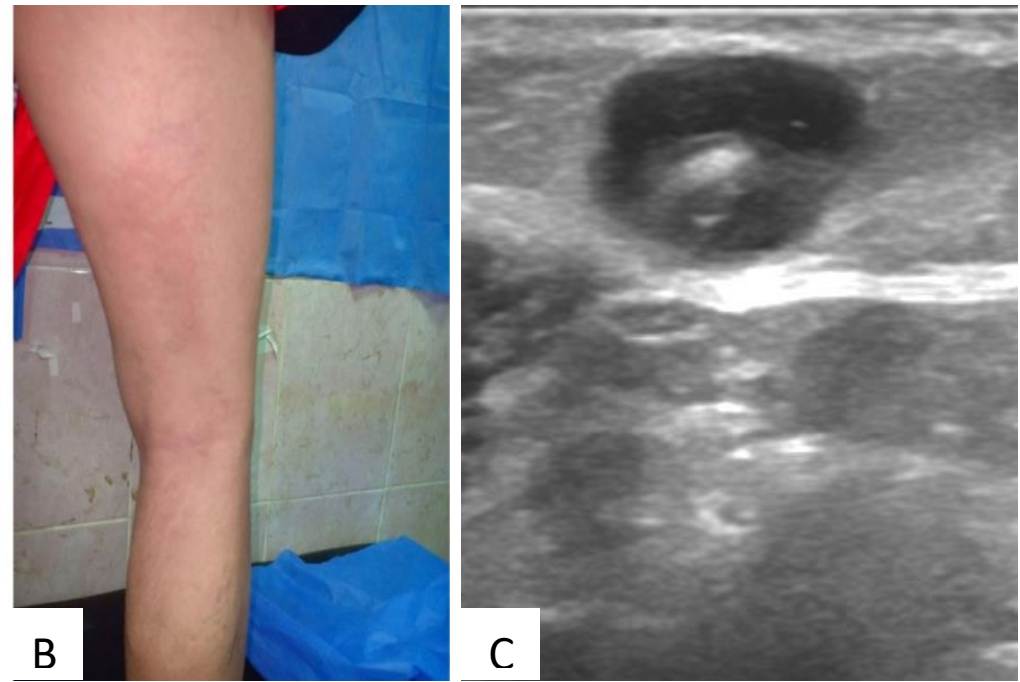

Figure(4). [37] Case no. 6: (A) Large sized subcutaneous varicosities seen at posterior aspect of thigh. (B) No visible varicose vein after UGFS. (C) Ultrasound showing complete thrombosis of treated vein.
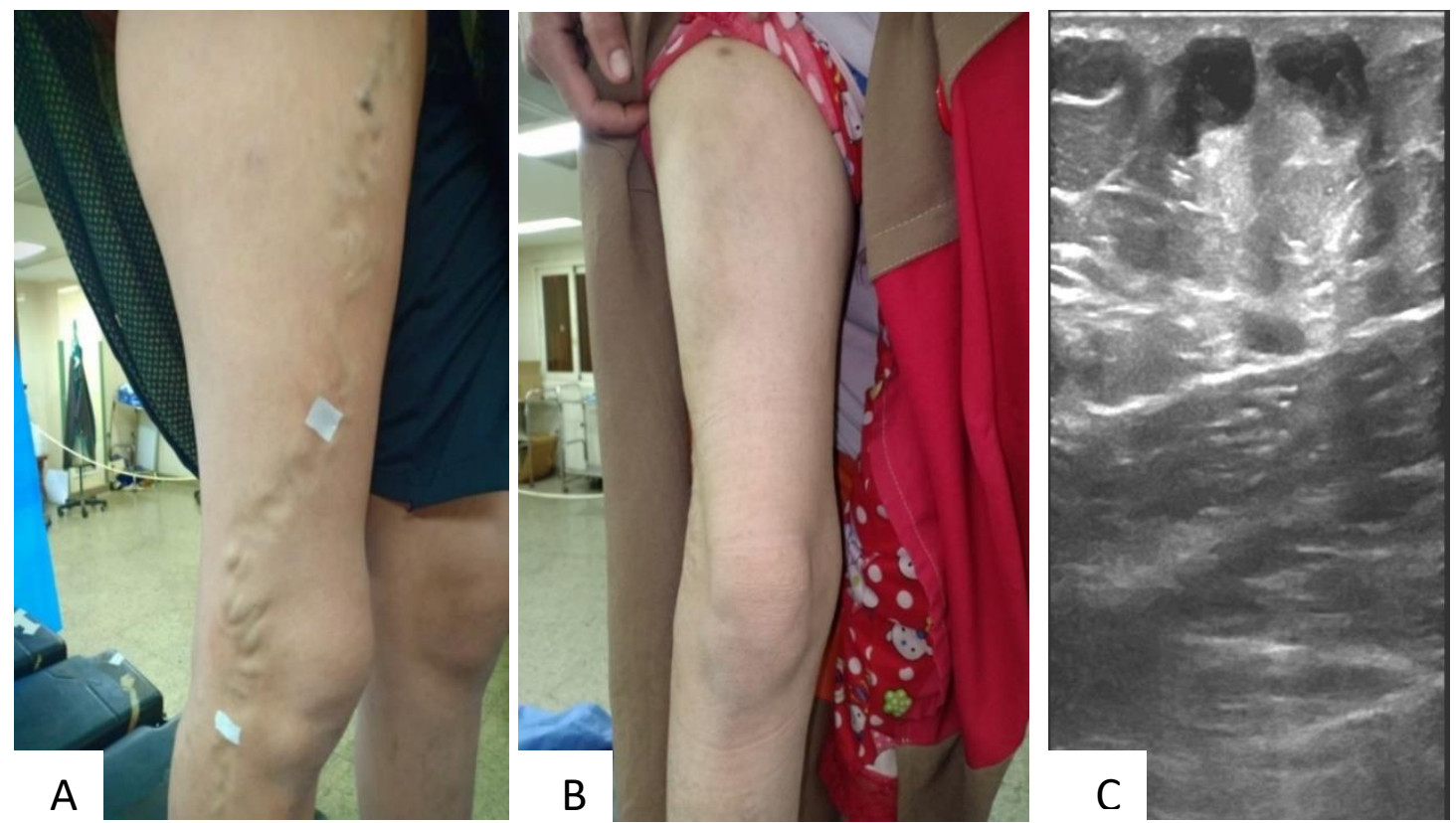

Figure(5). [38] Case no. 7: (A) subcutaneous varicosities related to refluxing large anterior accessory saphenous vein with abnormal course. (B) Disappearance of varicosities after UGFS. (C) Ultrasound image showing complete thrombosis of a treated vein with fibrosis changes. 